\title{
A VOZ DA MATA: OS TRAÇOS TESTEMUNHAIS EM ORÉ AWÉ ROIRU'A MA: TODAS AS VEZES QUE DISSEMOS ADEUS, DE KAKÁ WERÁ JECUPÉ
}

\section{THE VOICE OF THE FOREST: TESTIMONIAL ASPECTS IN KAKA WERÁ JECUPÉ'S ORÉ AWÉ ROIRU'A MA: WHENEVER WE SAID GOODBYE}

Iarima Nunes Redü ${ }^{1}$

\begin{abstract}
Resumo: O presente artigo tem como objetivo identificar os traços testemunhais constitutivos de Todas as Vezes que Dissemos Adeus, de Kaká Werá Jecupé. Além de buscar os traços testemunhais na narrativa de Jecupé e de identificá-los com a voz indígena do narrador, foi feita uma reflexão acerca das estratégias de elaboração da memória em uma narrativa autobiográfica. As definições de testemunho utilizadas como base para este trabalho foram fornecidas por Tempo Passado (2007) de Beatriz Sarlo, Narrar o trauma: A questão dos testemunhos de catástrofes históricas (2011) de Márcio Seligmann-Silva e A memória, a história, o esquecimento (2007) de Paul Ricoeur e os conceitos relativos a memória foram retirados de Memória e Identidade (2012) de Joël Candau.
\end{abstract}

Palavras-chave: Literatura indígena; Testemunho; Memória; Literatura e História.

Abstract: This paper aims at identifying Kaka Werá Jecupé's Whenever we said goodbye's constitutive testimonial aspects. Other than searching for the testimonial aspects of Jecupé's narrative and identifying them to the narrator's indigenous voice, one reflected on the strategies of memory elaboration into an autobiographical narrative. The testimonial concepts utilized on this paper were provided by Beatriz Sarlo's Tempo Passado (2007), Márcio Seligmann-Silva's Narrar o trauma: A questão dos testemunhos de catástrofes históricas (2011) and Paul Ricoeur's A memória, a história, o esquecimento (2007), while concepts regarding memory were furnished by Joël Candau's Memória e Identidade (2012).

Keywords: Indigenous literature; Testimonial; Memory; Literature and History.

\section{Considerações preliminares}

A literatura indígena ainda constitui um campo pouco explorado pelos estudos literários no Brasil. O número baixo de trabalhos publicados em periódicos que tematize a literatura produzida por indígenas, bem como de dissertações e teses que se debrucem sobre

\footnotetext{
${ }^{1}$ Mestranda no Programa de Pós-Graduação em Letras - Estudos Literários: Literaturas Portuguesa e LusoAfricanas da Universidade Federal do Rio Grande do Sul (UFRGS). E-mail: iarima.redu@gmail.com
} 
tal assunto, deve-se, pelo menos parcialmente, ao caráter incipiente de tal literatura no contexto brasileiro.

A literatura efetivamente produzida em primeira mão por indígenas, excetuando-se publicações de segunda via, "em formas reescritas ou transcritas por antropólogos, por folcloristas, ou até mesmo por autores infantis" (SOUZA, 2002), inicia-se no início da década de 1990 como reflexo direto do reconhecimento oficial da existência de línguas indígenas no Brasil promovido pela constituição de 1988. Um panorama das iniciativas de valorização da cultura indígena, as quais redundariam na formação e consolidação da literatura indígena escrita, é traçado por Cláudia Neiva de Matos:

\begin{abstract}
Iniciativas inovadoras e democratizantes em educação indígena multiculturalista, implementadas por ONGs e em seguida também por instituições governamentais, foram estimuladas pela evolução da legislação, em diversas etapas. A Constituição de 1988, rompendo com a tradição integracionista, consagra o direito dos índios à prática de suas formas culturais identitárias e assegura, no ensino fundamental, o uso das línguas maternas e o bilinguismo. Em 1991, um decreto presidencial possibilita a integração da escola indígena aos sistemas de ensino regular, sob responsabilidade do MEC e das secretarias municipais e estaduais de Educação. Pela Lei de Diretrizes e Bases da Educação Nacional de 1996, escolas bilíngues e interculturais devem propiciar aos povos indígenas, por um lado, a revitalização e/ou recuperação de seu patrimônio linguístico e cultural e, por outro lado, o acesso aos acervos e saberes da sociedade nacional e de outras sociedades indígenas e não indígenas. (MATOS, 2011, p. 30-31)
\end{abstract}

A inserção dos indígenas em uma cultura letrada que valorize as características específicas de sua cultura não só cria um público leitor nas aldeias, mas também fornece condições para que haja escritores entre os indígenas, os quais poderão ser lidos dentro e fora de seu contexto imediato, por um público indígena e não indígena. Se o escritor indígena produz em língua portuguesa, sua obra pode atingir um público maior e, consequentemente, sua mensagem ecoa mais longe, o que pode garantir que sua voz seja ouvida - diferentemente dos relatos etnográficos dos antropólogos, dos personagens indígenas em obras escritas pelo homem branco, agora o indígena pode falar, por si, sobre o que desejar.

Muitas vezes podem ser encontrados em livros escritos por indígenas traços testemunhais, relatos com características autobiográficas e com objetivos éticos: contar a história para que ela não se repita, dizer o que aconteceu para que as pessoas saibam. Entre os escritores que se engajam em relatos dessa natureza está Kaká Werá Jecupé, o qual tem se destacado não só por sua produção escrita, mas também por seu papel de representante da cultura ancestral em meios de comunicação de massa. O guerreiro sem armas txucarramãe, terapeuta da linhagem dos pajés, publicou quatro livros: Tupã Tenondé, A Terra dos Mil 
Povos: História Indígena do Brasil Contada por um Índio, As Fabulosas Fábulas de Iauaretê e Oré Awé Roiru'a Ma: Todas as Vezes que Dissemos Adeus.

Oré Awé Roiru'a Ma: Todas as Vezes que Dissemos Adeus, publicado por Jecupé em 1994 e reeditado em 2002, narra o trajeto do autor em busca de suas raízes ancestrais, percorrendo aldeias e passando por iniciações espirituais entre os povos tapuia e guarani. A narrativa, que é manifestamente autobiográfica, é desencadeada pela cerimônia do $\mathrm{Ni}$ mongaraí, o ritual de batismo, em que o até então Ka-ká Txukarramãe receberá um nome nandeva e será aceito como membro da tribo. A partir desse momento, o narradorprotagonista relembra seu caminho, desde a diáspora do povo de sua mãe e sua chegada à aldeia Krukutu, em São Paulo, até seu caminho de conscientização dos indígenas e dos brancos, no ritual do Anhangabaú-Opá, passando pela sua relação muitas vezes traumática com a sociedade branca.

Este ensaio tem como objetivo identificar os gestos testemunhais constitutivos de Todas as Vezes que Dissemos Adeus, de Kaká Werá Jecupé (doravante referido como Todas as Vezes que Dissemos Adeus) bem como de examinar a elaboração feita nessa obra das memórias do narrador e de sua cultura. As definições de testemunho utilizadas como base para este trabalho foram fornecidas por Tempo Passado (2007) de Beatriz Sarlo, Narrar o trauma: A questão dos testemunhos de catástrofes históricas (2011) de Márcio SeligmannSilva e A memória, a história, o esquecimento (2007) de Paul Ricoeur e os conceitos relativos a memória foram retirados de Memória e Identidade (2012) de Joël Candau.

\section{Minha cabeça troveja lembranças}

A reconstrução da memória é um elemento muito importante na criação de Todas as Vezes que Dissemos Adeus. A narrativa é constituída a partir das memórias da vida de Kaká Werá Jecupé e dos caminhos que ele trilhou "entre dois mundos" (JECUPÉ, 2002, p. 16), lembranças essas urdidas de forma a demonstrar os passos de sua trajetória, sua relação com a cultura ancestral e com a cultura ocidental, bem como de transmitir a mensagem milenar da cultura indígena à sociedade branca em colapso ambiental.

O relato narrativo de Kaká Werá parte das memórias do narrador-protagonista e manifesta um pensamento voltado para um futuro em que as relações entre brancos, indígenas e o mundo sejam mais harmoniosas. O presente de seu relato é representado como uma conversa ao pé do fogo entre ele e quem quiser ouvi-lo, em uma metáfora que carrega 
tradições culturais dos povos indígenas brasileiros. Pensar no futuro sempre com o passado e suas lições em mente e, assim, construir um relato com fins éticos, é uma atitude que pode ser relacionada ao ato de memória de Candau (2012, p. 59). Retomar o passado funciona, no caso dos escritores indígenas, como uma maneira não só de tomar a voz e narrar sua história sempre silenciada pelo discurso oficial, mas também como forma de afirmar essa história e constituir uma identidade frente às diversas outras etnias que compõem a sociedade brasileira.

É preciso, no entanto, ter sempre em mente que as memórias são uma "reconstrução continuamente atualizada do passado, mais do que uma reconstituição fiel do mesmo" (CANDAU, 2012, p. 9), sendo essa reconstrução baseada na lembrança de certos momentos e no esquecimento de outros. Os momentos escolhidos, conscientemente ou não, para serem recordados por um indivíduo ou por um grupo embasam a identidade desse indivíduo ou grupo. Daí que Candau afirma que a perda da memória é uma perda de identidade (2012, p. 59).

A narrativa de Kaká Werá apresenta bem essa relação entre memória e identidade em muitos momentos, dos quais é necessário ressaltar o cerimonial de batismo do Ni-mongaraí. Neste momento do livro, que é narrado no primeiro capítulo, o antigo Tiramãe Tujá revela ao então Kaká Txucarramãe o nome de sua alma, que indica a linhagem espiritual da qual ele provém. Depois de dançar o jeroky, sentam-se ao pé do fogo e Tiramãe Tujá conta uma história muito antiga, do tempo dos Tamãi, enquanto pitam do petenguá. Os mitos contados por Tiramãe Tujá em preparação para a revelação do nome da alma de Kaká Werá são os mitos de cosmogonia guarani-nandeva:

Tupã (acendeu o petenguá com o vermelho do carvão da fogueira) quando sopra sua fala-canto, tudo se cria... a vida; ovo primeiro, é sopro do petenguá de Tupã, a vida é o oka-vusu, é fogo exalado de seu hálito, fazendo um o que é dois, fazendo o três, fazendo o quatro, fazendo a mão... (JECUPÉ, 2002, p. 20)

Os mitos de origem de um povo são um fator muito importante para a consolidação de sua identidade, já que podem ser vistos como uma das memórias mais antigas de cada etnicidade. Esses mitos se situam, segundo Candau (2012, p. 96), em tempos inacessíveis à experiência humana, mas, ainda assim, condicionam a vida presente dos sujeitos que os compartilham. Ainda de acordo com Candau, quando os povos são, entretanto, amputados de seus mitos de origem, a elaboração que os membros desses povos podem fazer de sua identidade acaba se tornando fragmentária e incerta, caso que pode ser aplicado ao povo brasileiro como um todo - que teve seus mitos indígenas apagados pela colonização 
portuguesa -, mas não totalmente às etnias indígenas que sobreviveram, uma vez que esses mitos são transmitidos entre gerações pelos mais velhos mediante momentos como o narrado por Kaká Werá. Ainda assim, o silenciamento dos mitos indígenas é um apagamento que pode dificultar a integração e a identidade comum do povo brasileiro, que parece muitas vezes rejeitar os costumes indígenas ou alterar a origem desses costumes, atribuindo-os a outras culturas, mais prestigiadas.

Além de visões da cosmogonia guarani-nandeva, Tiramãe Tujá narra o mito de origem dos homens de acordo com os nandeva, identificando a alma ao som de um sopro, vindo de Tupã, palavra encarnada:

Olhe em volta, tudo é o Pai cósmico que orienta esse 'espírito-música-dança', para que se desdobre em continuação na 'grande Vida'. Em seu desdobrar, o sopro do nome desliza por um dos Quatro Cantos. Mandados por um dos sete 'Raios-Pai' desdobrados de Tupã. [...] Por esta respiração sagrada o 'espírito-nomeado' contempla seu último desdobrar, indobrando-se na Terra virando semente, depois é que a pequena mãe terrena concebe o corpo do nome na barriga. (JECUPÉ, 2002, p. 20-21)

Alhures no livro, Kaká Werá refere-se ao tempo em que sua mãe esteve grávida de si como "quando eu era música entonada na barriga de minha mãe" (Jecupé, 2002, p. 22). A alma, então, está diretamente ligada ao som do nome e antes de se saber o nome da alma, os indígenas apenas existem sobre a terra.

O ápice do capítulo é o momento em que o antigo Tiramãe Tujá revela o nome da alma de Kaká Txucarramãe. Esse momento, pensando que o nome é o som do sopro de Tupã que encarnou, é decisivo na vida dos guarani:

-Teu nome nandeva, tua alma-palavra... é...

Pôs a mão na minha cabeça, soprou a fumaça do petenguá, derramou água com sagradas ervas...

-Werá Jecupé. - Arrepiei-me.

-Não é mais um apelido, Ka-ka Txukarramãe. Espere e virá a confirmação. Kaká Werá Jecupé.

Apontou a direção de onde viera o nome. O sol encheu meu novo corpo. (JECUPÉ, 2002, p. 21)

O nome é tão importante que, ao receber a revelação do nome de sua alma por parte do mais velho, o narrador afirma ter um corpo novo. A nomeação é muito relevante no que diz respeito à memória e à identidade de um indivíduo. Candau afirma que há uma forte ligação entre a perda do nome e a perda da memória e que a aniquilação da memória e da identidade entre classes de deportados (como, por exemplo, os judeus enviados para os lager nazistas) 
vem antes de sua exterminação física sob a forma da substituição dos nomes das pessoas por números de registro (CANDAU, 2012, p. 67).

A nomeação também tem grande relevância no caso dos povos indígenas, ainda que seu ritual seja diferente. Os indígenas adquirem real participação no mundo quando são batizados, quando o nome de suas almas lhes é revelado, embora haja muitos que não sabem o nome de sua alma ou que preferem adotar nomes ocidentalizados:

A música-ser, o nome, na época dos antepassados, era anunciado pelo espírito guardião do casal. Hoje, muitos nascem e crescem sem nomes ou com nomes impostos, chamam de nomes civilizados, 'nomes números', e acabam não realizando a sua dança pessoal, a sua pintura própria, o seu canto próprio, porque os jaguares interferem tanto que mascam-lhes a memória e a raiz ancestral. (JECUPÉ, 2002, p. 24-25)

Comparando a citação anterior ao que foi dito sobre a relação entre memória e identidade, nos termos expostos por Candau, percebe-se que o narrador faz um julgamento sobre o apagamento da cultura ancestral e o relaciona aos indígenas que não querem se relacionar com as tradições: os indígenas perdem a memória por terem nomes números e, consequentemente, não podem afirmar sua identidade própria por abandonarem a chance de dançar sua própria dança.

A semelhança entre o que é preconizado por Joël Candau e o que é narrado por Kaká Werá Jecupé é marcante. Candau afirma que apagar o nome de um indivíduo é negar sua existência, sua identidade; ora, se entre os indígenas jovens há muitos que sequer sabem seus nomes, que tipo de identidade eles podem ter? Sua memória ancestral lhes é negada desde o nascimento, desde seu registro em um mundo ocidentalizado que suprimiu a cultura de seu povo de maneira impiedosa.

Retomando a relação entre nome e corpo, parece importante citar a passagem de Todas as vezes que dissemos adeus em que o narrador-protagonista é levado à escola. Apesar de se sentir fascinado pela capacidade da escrita de capturar e eternizar o que se diz, o menino é forçado a tirar uma foto para o registro da escola e recebe um nome civilizado. Essa interferência direta da cultura branca sobre a criança é responsável pela morte da mãe:

Como era nome novo, de mi tã, não cheguei a ficar doente, mas poderia ficar esquecido de mim. A mãe cantou durante três dias todas as palavras que compunham minha música - coisa que só as mães sabem - para que nada de ruim acontecesse. [...] Mas a mãe não resistiu aos novos costumes, ou às velhas saudades, não sei, talvez não tenha resistido à passagem da vida desmoronando diante dos olhos. O fato é que ela escolhera morrer cautelosamente, procurando não deixar 
qualquer marca na lembrança. Foi um dia perdido na infância, em que suas ervas não conseguiram curar minhas lágrimas. (JECUPÉ, 2002, p. 33)

Essa experiência traumática vivida pelo então Kaka-txai-jé Txucarramãe é um dos momentos de despedida aos quais o título do livro alude. Há pelo menos mais duas despedidas marcantes, ambas desencadeadas, como a morte da mãe, pelo contato com o branco. São os momentos em que morrem seu amigo Kalingué-Poku, ainda na infância, e seu pai, no início da adolescência.

Kalingué-Poku ensina o narrador-protagonista a nadar. Os dois nadam na represa que circunda a aldeia, a poluída Billings - "mergulhamos nas grossas águas da represa que nos cercava e delimitava a aldeia" (JECUPÉ, 2002, p. 30) -, o que causa a morte de Kalingué e uma grave doença em Kaká.

Quando melhorei, fui chamar meu amigo para brincar. Havia morrido. Fez a passagem do tempo. Não resistiu. Não iríamos mais atrás do segredo das panambis as borboletas. Sua família entoava cantos de dor e eu chorei. Não sabia, mas sem querer iniciava a delicada lição na arte de dizer adeus. (JECUPÉ, 2002, p. 30)

O envenenamento das duas crianças indígenas por mergulharem na represa é um contato traumático entre a cultura ancestral e a cultura ocidental que aprofunda $o$ distanciamento, ainda que de maneira latente, do menino que sobreviveu em relação à cidade com coração de jaguar. A civilização que polui, que age "fazendo os rios correrem ao contrário de si”, fluindo morte ao invés de vida (JECUPÉ, 2002, p. 38) é que tornou as águas da represa insalubres e, consequentemente, começou a ensinar a arte do adeus.

O pai de Kaká morre depois que a aldeia é expulsa do lugar que ocupava por um senhor munido de documentos que comprovavam sua posse daquele terreno. Pai e filho se deslocam até a Aldeia de Peruíbe antes de se estabelecerem na Aldeia Morro da Saudade. Nesse ínterim, um senhor do vilarejo vizinho à aldeia ensinou o pai de Kaká a "tomar certo líquido que dizia anestesiar as feridas do espírito" (JECUPÉ, 2002, p. 38), o que constitui mais uma interferência da cultura ocidental sobre os hábitos indígenas. O pai de Kaká passou a beber cada vez mais, morreu e, depois de sua morte, o filho afirma definitivamente sua revolta em relação à cultura ocidental:

O pai, no início, passou a bebê-lo [o líquido ardente], mas depois, com as luas, o líquido é que lhe bebia. Liquidava-se. E o tempo fez com que sobre uma velha canoa de pesca seu corpo esquecido anoitecesse sob as últimas estrelas da sua vida. Sendo que a represa ainda lhe consentiria a graça de trazê-lo esparramado com a manhã, dentro de um grosso e oleoso ritual. Foi a partir daí que empunhei a lança da revolta. (JECUPÉ, 2002, p. 39) 
A memória, constituída de momentos que se deseja lembrar e de momentos selecionados para serem esquecidos, às vezes impõe a dor como lembrança importante. É o caso das despedidas em Todas as vezes que dissemos adeus, que ocupam lugar de destaque na obra e serão tomadas, aqui, como ponto de partida para outra discussão importante deste ensaio: o testemunho.

\section{Para que a boa reflexão do que foi dito possa servir de húmus para a humanidade}

A identidade é construída pelas lembranças guardadas e esquecidas, escolhidas pela memória, que formam uma espécie de relato de cada um. Selecionar e organizar memórias é uma maneira de os seres humanos marcarem sua individualidade em relação aos grupos aos quais pertencem, é uma maneira de tentar se situar no mundo e de compreender, em alguma dimensão, o tempo. O mundo é organizado estruturalmente e passa a fazer sentido para os homens a partir da memória (CANDAU, 2012, p. 61), mas esse sentido só é possível a partir da verbalização do passado, da narrativização dos momentos e de sua construção como um relato. As narrativas sobre as vivências humanas, além de determinarem identidades e visões de mundo, também podem ser vistas como uma maneira de resistir ao tempo inexorável. Conforme Candau (2012, p. 72-73), “a memória é também uma arte da narração que envolve a identidade do sujeito e cuja motivação primeira é sempre a esperança de evitar nosso inevitável declínio.”.

Todas as vezes que dissemos adeus é uma narrativa que ordena a memória de Kaká Werá Jecupé e que, não sendo elaborada somente no sentido de consolidar a identidade do narrador, expõe as diferenças entre a cultura ancestral dos indígenas brasileiros e a cultura da civilização hegemônica, esta sempre silenciando aquela. O narrador está vinculado à experiência que viveu e que narrativiza para ensinar alguma coisa dos Tamãi para os membros da civilização ocidental. Nesse sentido, que pode ser confirmado em diversos momentos ao longo do livro, é possível notar um comprometimento ético da obra em relação ao passado aniquilado de um povo e do futuro desse povo e do mundo inteiro, um engajamento que liga o texto de Jecupé à corrente de textos calcados em experiências traumáticas que compõe a literatura de testemunho.

O testemunho estabelece ligações inequívocas com uma experiência factual que se desenvolve no plano da história. Paul Ricoeur identifica no testemunho uma "asserção de realidade" que advém do "acoplamento" aos fatos narrados (2007, p.170). Ricoeur afirma, 
ainda, que a palavra do testemunho, devido a esse acoplamento, insere-se em uma dimensão de "ordem moral" e reivindica para si, ainda que de maneira problemática, "credibilidade e confiabilidade" (RICOEUR, 2007, p.174).

Os testemunhos de experiências extremas são aqueles que resistem à explicação historiográfica, tornando o arquivamento um meio inapropriado para sua inserção na história, uma vez que a experiência a ser comunicada "é a de uma inumanidade sem comparação com a experiência do homem comum" (RICOEUR, 2007, p.186). Assim, a manifestação do testemunho na literatura assegura o registro das experiências violentas e traumáticas que não foram contempladas pelo discurso historiográfico oficial.

No caso de Todas as vezes que dissemos adeus, as experiências extremas sofridas pelo povo indígena desde o início da colonização brasileira são enfocados pelo narrador e narradas a partir do que sua família vivenciou:

\begin{abstract}
Quando eu era música entonada na barriga da mãe a nossa aldeia foi atacada. Homens empunhados de pequenos trovões de aço fizeram uma grande tempestade; lançando-se contra nós de todos os lados, fazendo chuva de chamas. Curumim, cunhã, tijari, tieti, mitã, menononure, aymeri, tujá, tujá-i; corpos destes nomes ao chão, como um estio fúnebre. Quando a última oca derramou sua última lágrima de fogo e se desfez em cinza, restaram pouco mais de oito parentes, entre eles a anciã Meirê-Mekrangnotire e a filha Yakamara, que viria a ser a mãe que me semearia no mundo. (JECUPÉ, 2002, p. 22)
\end{abstract}

Além dessa passagem, que narra a diáspora da família de sua mãe e a obrigação de buscar outra aldeia, em vários outros momentos da narrativa há a alusão ao genocídio indígena, como no início do capítulo "Entradas e Bandeiras". Neste trecho do livro, o narrador-protagonista está em São Paulo, lutando junto com os guerreiros verdes da metrópole em prol dos direitos dos indígenas que estava prestes a ser expulso da Casa do Índio. A manifestação se desenrola em frente ao Monumento às Bandeiras - "todos olhares de pedra, todos os corpos de pedra inclinados puxando a canoa do começo do povo civilizado em São Paulo" (JECUPÉ, 2002, p. 68) -, grande estátua de mármore "pesando sobre o chão responsabilidades da história paulista." (JECUPÉ, 2002, p. 68) que fica perto do Parque Ibirapuera.

Kaká Werá Jecupé não deixa de relacionar tais responsabilidades do povo paulista, responsável pelo processo de alargamento das fronteiras brasileiras conhecido como Entradas e Bandeiras, ao desaparecimento do povo guaianá, que habitou aquela região "bem antes do século XVI, cuja aventura deixou apenas a alma do nome: Ibirapuera.” (2002, p. 68). Esse 
processo de expansão do domínio português foi, de fato, responsável pela dizimação da maioria dos povos indígenas brasileiros e pela consequente aniquilação de muitas culturas das quais não pode haver testemunho.

Retomando a discussão acerca das caraterísticas da literatura de testemunho, é preciso ressaltar que a ficcionalidade ou imaginação não anula o "teor testemunhal" de uma narrativa, devendo, antes, ser "como arma que deve vir em auxílio do simbólico para enfrentar o buraco negro do real do trauma" (SELIGMANN-SILVA, 2008, p.70) ou, conforme Beatriz Sarlo (2007, p. 41), a imaginação deve sair de visita a fim de que possa haver um distanciamento reflexivo entre a experiência e o relato. Nesses termos, o testemunho na literatura não apaga a experiência factual relacionada a um evento traumático da história, mas redimensiona-a e opera uma transformação dessa experiência factual em uma manifestação de linguagem simbólica. A realidade a que o testemunho se reporta é a experiência que, pelo trabalho de ficção, ressoa na memória coletiva do evento histórico. A natureza peculiar dessas narrativas comprometidas com o "real" exige um "redimensionamento do conceito de literatura. A relação desse autor com o passado ao qual ele tenta dar uma forma tem o caráter de um compromisso ético" (SELIGMANN-SILVA, 2003, p.382). Esse dado é essencial na caracterização da literatura de testemunho, especialmente tendo em mente que esse compromisso transcende a condição tradicional de testemunho, já que a impossível relação direta entre o sujeito testemunhal e o evento traumático ao qual se refere não é o que sustenta o testemunho: é a elaboração discursiva do evento traumático que cumprirá este papel, é sua transformação em elemento literário, em linguagem simbólica.

A literatura de testemunho une, portanto, ética e estética por meio da elaboração simbólica dos eventos traumáticos vividos pelo representante de um povo que sofreu catástrofes quase inenarráveis, as quais são narrativizadas com a finalidade de expurgar o evento traumático ou de alertar para que tal evento não se repita. Em Todas as Vezes que Dissemos Adeus, o comprometimento ético do narrador é reiteradamente manifesto. $\mathrm{O}$ primeiro momento em que o desejo do narrador de assumir o papel de ponte entre as culturas indígena e branca e, assim, fazer ouvir o testemunho de seu povo aparece é já no prólogo:

Sonhei que os Tamãi deram-me a incumbência de contar um pouco da minha história, da minha vida entre dois mundos, e de revelar alguns mistérios da tradição milenar ensinada pelos Antigos, os que aqui habitavam desde sempre.

Neste sonho firmei o compromisso de traduzir da vermelha 'escritura-pintura' de meu corpo para o branco corpo desta 'pintura-escrita'. [...] E nesse contar eu sou o espírito de cada folha, cada planta, cada brisa pronunciada. [...] Eu sou a voz da terra pisada assim como da terra tocada. Pois aceitei por inteiro a missão de ser um porta- 
voz à surda metrópole com seus ornamentos de néon e a beleza cosmética de sua face, cujos antepassados vestiram o meu povo de costumes, hábitos, espelhos. (JECUPÉ, 2002, p. 16)

Percebe-se a incumbência do narrador e sua aceitação de mediar as duas culturas, de passar adiante a sabedoria ancestral e, principalmente, de lembrar a civilização da importância de cuidar da natureza, "para ensolarar turvas sombras, perigosas, de jaguares, capazes inclusive de fazer com que, por ignorância, destruam a grande Mãe.” (JECUPÉ, 2002, p. 1617).

O testemunho de alguém que pertence a uma cultura e a uma etnia consideradas inferiores ou, pelo menos, tratadas dessa forma ao longo dos últimos séculos só pode pretender ser ouvido se for composto nos termos da cultura dominante. Isso acontece em Todas as Vezes que Dissemos Adeus pois Kaká Werá Jecupé foi “empurrado na boca do jaguar, essa yauaretê chamada metrópole" (JECUPÉ, 2002, p. 16) de forma que aprendesse de sua língua e de sua cultura. Assim, devorando o cérebro da cidade, sua voz poderia ser ouvida.

O contato do narrador-protagonista com a cidade e seus habitantes, aliás, é emblemático do caminho que ele trilha entre a revolta, posterior à morte de seu pai, e o perdão, levado a cabo na grandiosa cerimônia do Anhangabaú-Opá. Nos momentos de raiva, o narrador afirma que as pessoas da cidade, que é feita de um asfalto estéril e plena de frutas artificiais, têm o jaguar no coração, são gananciosas e vivem de falas artificiosas:

Com o tempo, passei a andar pelas largas trilhas da cidade chamadas avenidas. Percorri suas florestas de aço e comi de seus frutos artificiais para descobrir os brasis. No asfalto por onde andei, se plantando nada dá. Provei do bom e provei do ruim. Conheci uma qualidade de caciques [...] que, como dizia um antiquíssimo e histórico escrivão, andam deveras desavergonhados. Eles têm requintes na fala, vivem dela. E o jaguar no coração (Sim, o jaguar que devora tudo que seja contrário ao seu único olho cego). E acabei por descobrir que muitos deles eram a causa do extermínio de meu povo. (JECUPÉ, 2002, p. 37)

Depois da complexa dança de realização do Anhangabaú-Opá, grande rito de perdão de "fím do vale dos velhos anhans" (JECUPÉ, 2002, p. 73) que envolveu a participação de vários outros povos e religiões, o tom de Kaká Werá é outro ao relembrar os passos da dança realizada na metrópole, sobreposta às falas artificiosas dos jaguares:

Os Tamãi, os nossos ancestrais, concederam o perdão porque veem pelo alto e enxergam cada um pela música que são e não pelas palavras que pronunciam. $\mathrm{O}$ mundo esqueceu-se de sua fala sagrada. Até mesmo meu povo, cujos anciãos velam o sagrado dizer, muitas vezes deixa sair pela boca flechas de curare. [...] Hoje, por aqui, comemoro por mim mesmo o fim daqueles velhos anhans daquele vale. 
Comemoro com a noite. Os velhos anhans não amanheceram o dia, pois o sol seguinte trouxe a comunidade judaica inundando aquele lugar da branca luz de centenas de pombos em voo festejando a paz do acordo entre árabes e israelenses. [...] Agora o nome do vale estava oco. Vazio do mal que havia. (JECUPÉ, 2002, p. 104-105)

Embora a literatura de testemunho se desenvolva em dois campos bem delimitados e distintos, o da Shoah dos sobreviventes dos campos de concentração nazistas e o do testimonio latino-americano das vítimas dos regimes ditatoriais do século XX (MARCO, 2004), as características apresentadas anteriormente parecem autorizar a análise de Todas as vezes que dissemos adeus sob a luz do testemunho. Não se pretende com este ensaio modificar o campo de estudos da literatura de testemunho ou tentar ampliá-lo de alguma maneira, e sim estudar certos gestos testemunhais do relato narrativo de Kaká Werá Jecupé.

Depois de abordar esses aspectos éticos da obra em estudo e o desejo de impacto social da narrativa de Kaká Werá Jecupé, parece relevante trazer a prova pessoal e individual por que o guerreiro sem armas, designação do povo Txucarramãe, passou antes de encontrar o Mboraí e de totalmente compreender sua função no mundo. Na nova primeira missa do Brasil, realizada antes do Anhangabaú-Opá na Catedral da Sé por representantes de muitas religiões, o ainda aprendiz menboktire Kaká Werá Jecupé fala de sua vida e da experiência de seu povo diante de todos e, sem bem compreender seus atos no momento, atira as flechas que carregava no chão e entrega rosas brancas aos líderes das outras religiões. Depois, relembrando esse momento, ele reflete:

\begin{abstract}
A mim não era mais dado olhar a vida como um menboktire. Já sentia-me começar a pulsar como um menononure. Fiz o ato de passagem. Uma vez Tiramãe Tujá disse que as provas que temos que passar na vida, seja onde for, estejamos onde quer que seja o lugar, jamais deixarão de surgir a nós. E o ensinamento antigo, que vem de antes de o tempo tecer sua plumagem, de que um Txukarramãe somente torna-se um Txukarramãe quando definitivamente atira suas armas no chão diante de sábios, guerreiros e pajés; coube a mim cumpri-lo, não dentro da mata virgem, mas da cidade, na Catedral da Sé. Com todas as situações adversas. E ainda assim joguei ao chão a flecha do passado presa na garganta, a flecha da omissão. (JECUPÉ, 2002, p. 105-106)
\end{abstract}

A bela cena em que o guerreiro se despe de suas lanças e entrega rosas brancas aos outros povos é o símbolo do trajeto pelo qual os indígenas foram forçados a passar e que a narrativa de Jecupé parece sugerir que os outros povos, ditos civilizados, também se disponham a percorrer.

\title{
Considerações finais
}


A narrativa de Kaká Werá Jecupé é uma narrativa de perdão e de conscientização, mas não de esquecimento. Os males representados pelo nome do vale do Anhangabaú, purificado no ritual do Anhangabaú-Opá, e lugar central (até geograficamente) que esse mal ocupa na civilização ocidental que se estabeleceu no Brasil às custas da aniquilação de muitas culturas ancestrais, foram lavados naquele rito, mas não apagados da história. De fato, ainda que inebriado pela sua passagem de menboktire a menononure, Kaká Werá lucidamente vê que todo o perdão de sua história e da história de tantos povos é esquecida diante da grande sociedade, alimentada por uma mídia que só noticia desastres:

\begin{abstract}
Quando disse a Tiramãe Tujá dessa prova, comentei que, embora um rito pessoal, talvez servido somente a mim mesmo, aquele desejo [de harmonia entre os povos] era grande. Mas as câmaras, os olhos eletrônicos da civilização, só viam mesmo o massacre, era o que interessava vender aos lares civilizados. Somente as grandes tragédias e não os pequenos grandes sonhos. Assim como ninguém viu pela TV as pombas judaicas brasileiras voarem pela paz. (JECUPÉ, 2002, p. 106)
\end{abstract}

Por motivos como esses, reconhecidos no âmago de um relato que pretende ser ponte entre povos e carregar os conhecimentos ancestrais para o mundo civilizado, é que narrativas testemunhais como a de Kaká Werá Jecupé, fortemente carregadas de memórias silenciadas pela grande civilização, são necessárias.

A elaboração estética das lembranças de alguém que carrega tanto conhecimento e que, mesmo tendo seu povo sido exterminado ao longo de séculos por outras pessoas e vendo a natureza ser conspurcada pelos perpetradores do extermínio, tem forças para perdoar e alertar, purificando as duas culturas, deve ser levada para dentro da academia. O estudo de obras como Todas as Vezes que Dissemos Adeus, sob quaisquer perspectivas, só pode enriquecer o debate acadêmico em diversas áreas das Ciências Humanas.

\title{
REFERÊNCIAS
}

CANDAU, Joël. Memória e identidade. São Paulo: Editora Contexto, 2012.

JECUPÉ, Kaká Werá. Oré awé roiru'a ma: todas as vezes que dissemos adeus. São Paulo: TRIOM, 2002.

MARCO, Valéria. A Literatura de Testemunho e a Violência de Estado. In: Lua Nova, 62, 2004 (45-68).

MATOS, Cláudia Neiva de. Escritas indígenas: uma experiência poético-pedagógica. Boitatá (UEL), Londrina/PR, v. 12, p. 29-51, 2011. Disponível em: http://www.uel.br/revistas/boitata/volume-12-2011/B1203.pdf. Acesso em 26 de julho de 2013. 
RICOEUR, Paul. O testemunho. A memória, a história, o esquecimento. Trad. Alain François etal. Campinas, SP: UNICAMP, 2007 (p.170-176).

SARLO, Beatriz. Tempo passado. Cultura da memória e guinada subjetiva. São Paulo; Belo Horizonte: Companhia das Letras/Ed. UFMG, 2007.

SELIGMANN-SILVA, Márcio. (org.) História, memória, literatura: O Testemunho na Era das Catástrofes. Campinas, São Paulo: Unicamp, 2003.

SOUZA, Lynn Mario Trindade Menezes de. As visões da anaconda: a narrativa escrita indígena no Brasil. Semear (PUCRJ), Rio de Janeiro, v. 7, p. 223-236, 2002. Disponível em: http://www.letras.puc-rio.br/unidades\&nucleos/catedra/revista/7Sem 16.html. Acesso em 25 de julho de 2013. 